\begin{tabular}{|c|c|c|c|c|}
\hline \multicolumn{4}{|c|}{ НАУЧНО-ТЕХНИЧЕСКИЙ ВЕСТНИК ИНФОРМАЦИОННЫХ ТЕХНОЛОГИЙ, МЕХАНИКИ И ОПТИКИ } & \multirow[b]{2}{*}{ 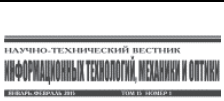 } \\
\hline 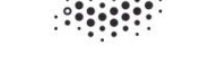 & $\begin{array}{ll}\text { май-июнь } 2016 & \text { Том } 16 \text { № } 3 \\
\text { SCIENTIFIC AND TECHNICAL JOURNAL } 0\end{array}$ & $\begin{array}{l}\text { ISSN 2226-1494 } \\
\text { NFORMATION TEC }\end{array}$ & $\begin{array}{l}\text { http://ntv.ifmo.ru/ } \\
\text { ECHANICS AND OPTICS }\end{array}$ & \\
\hline УНИВЕРСИТЕТ ИТМО & May-June 2016 & ISSN 2226-1494 & http://ntv.ifmo.ru/en & \\
\hline
\end{tabular}

УдК 629.7

ЭКОЛОГИЧЕСКИ ЧИСТЫЙ СПОСОБ СЖИГАНИЯ ГАЗООБРАЗНОГО

ТОПЛИВА С ПРИМЕНЕНИЕМ КВАЗИОПТИЧЕСКОГО СВЧ-ПУЧКА

П.В. Булат ${ }^{a}$, М.П. Булат ${ }^{a}$, И.И. Есаков ${ }^{\text {, И.А. Волобуев }}{ }^{\text {a,c }}$, Л.П. Грачев ${ }^{\text {, }}$,.В. Денисенко

а Университет ИТМО, Санкт-Петербург, 197101, Российская Федерация

b Московский радиотехнический институт РАН, Москва, 117519, Российская Федерация

' ООО «ВНХ-Энерго», Санкт-Петербург, 198035, Российская Федерация

d Университет Уорвика, Ковентри, CV4 7AL, Великобритания

Адрес для переписки: pavelbulat@mail.ru

Информация о статье

Поступила в редакцию 01.04.16, принята к печати 25.04.16

doi: 10.17586/2226-1494-2016-16-3-513-523

Язык статьи - русский

Ссылка для цитирования: Булат П.В., Булат М.П., Есаков И.И., Волобуев И.А., Грачев Л.П., Денисенко П.В. Экологически чистый способ сжигания газообразного топлива с применением квазиоптического СВЧ-излучения // Научно-технический вестник информационных технологий, механики и оптики. 2016. Т. 16. № 3. С. 513-523. doi: 10.17586/2226-1494-2016-16-3-513-523

\title{
Аннотация
}

Предмет исследования. Рассмотрена проблема разработки малоэмиссионных камер сгорания с уменьшенным выбросом окислов азота $\mathrm{NO}_{\mathrm{x}}$, работающих на природном или сжиженном газе. Изучена возможность сжигания особо бедных топливных смесей. Для инициирования зажигания и стабилизации горения используется разряд, сгенерированный квазиоптическим СВЧ-излучением. Основные результаты. При инициировании зажигания стримерным разрядом получено увеличение скорости горения примерно в четыре раза по сравнению с обычным искровым зажиганием и существенное увеличение полноты сгорания. Продемонстрировано зажигание стримерным разрядом особо бедной топливно-воздушной смеси с коэффициентом избытка окислителя больше предела воспламенения при нормальных условиях. Судя по косвенным признакам, при инициировании горения СВЧ-разрядом, созданным квазиоптическим излучением, зажигание имеет нетепловой характер. СВЧ-разряд возбуждает атомы кислорода, в результате чего генерируется мощное ультрафиолетовое излучение, которое вызывает образование холодной неравновесной плазмы с лавинообразным нарастанием числа свободных электронов. Стримерный разряд распространяется со скоростью порядка 5 км/с, поэтому инициирование зажигания происходит сразу по всему объему. Температура топливной смеси в месте инициирования зажигания не превышает 400 К. За счет отсутствия при горении областей с высокой температурой, которые ответственны за термический механизм Зельдовича образования $\mathrm{NO}_{x}$, а также за счет высокой скорости горения, в результате чего не успевает развиться механизм Фенимора образования «быстрых $\mathrm{NO}_{\text {x"}}$, судя по всему, исключается образование $\mathrm{NO}_{\mathrm{x}}$ в заметных количествах. Затраты энергии сравнимы с искровым зажиганием. Практическая значимость. Изучаемая технология предназначена для внедрения в области двигателей внутреннего сгорания, энергетических газовых турбин, газотурбинных газоперекачивающих агрегатов, работающих на природном газе.

Ключевые слова

малоэмиссионные камеры сгорания, квазиоптическое СВЧ-излучение, холодная неравновесная плазма, сжигание бедных топливных смесей, эмиссия оксидов азота

Благодарности

Исследование выполнено при финансовой поддержке Министерства образования и науки Российской Федерации (соглашение № 14.575.21.0057, уникальный идентификатор прикладных научных исследований RFMEFI57514X0057).

\section{ENVIRONMENTALLY FRIENDLY METHOD OF GASEOUS FUEL COMBUSTION WITH THE USE OF QUASI-OPTICAL MICROWAVE}

\section{P.V. Bulat ${ }^{a}$, M.P. Bulat ${ }^{a}$, I.I. Esakov ${ }^{b}$, I.A. Volobuev ${ }^{\text {a,c }}$, L.P. Grachev ${ }^{b}$, P.V. Denissenko}

a ITMO University, Saint Petersburg, 197101, Russian Federation

${ }^{\mathbf{b}}$ Moscow Radiotechnical Institute of the Russian Academy of Sciences, Moscow, 117519, Russian Federation

${ }^{\mathrm{c}}$ VNH-Energo, Saint Petersburg, 198035, Russian Federation

${ }^{\mathbf{d}}$ Warwick University, Coventry, CV4 7AL, United Kingdom

Corresponding author: pavelbulat@mail.ru

Article info

Received 01.04.16, accepted 25.04.16

doi: 10.17586/2226-1494-2016-16-3-513-523 
Article in Russian

For citation: Bulat P.V., M.P. Bulat, Esakov I.I., Volobuev I.A., Grachev L.P., Denissenko P.V. Environmentally friendly method of gaseous fuel combustion with the use of quasi-optical microwave. Scientific and Technical Journal of Information Technologies, Mechanics and Optics, 2016, vol. 16, no. 3, pp. 513-523. doi: 10.17586/2226-1494-2016-16-3-513-523

Abstract

Subject of Research. The paper deals with the problem of developing low emission combustors operating on natural gas or LPG, to reduce emissions of nitrogen oxides $\mathrm{NO}_{\mathrm{x}}$. The possibility of burning very lean fuel mixtures is studied. To initiate the ignition and combustion stabilization the discharge generated by the quasi-optical microwave is used. Main Results. Initiating ignition by streamer microwave discharge increases the rate of combustion and combustion efficiency about four times as compared with the conventional spark ignition. Streamer discharge ignition by very lean fuel-air mixture is demonstrated with the factor of oxiding agent excess greater than the limit of explosive range under normal conditions. According to indirect indicators, ignition by microwave discharge created by quasi-optical radiation is of non-thermal nature. Microwave discharge excites oxygen atoms, and intense ultra-violet radiation is generated as a result that causes formation of cold nonequilibrium plasma with avalanche growth of free electrons. Streamer discharge propagates at a speed of $5 \mathrm{~km} / \mathrm{s}$, so the initiation of the ignition occurs immediately throughout. The temperature of the fuel mixture at the point of ignition initiation does not exceed $400 \mathrm{~K}$. There is no area with a temperature sufficient to initiate thermal Zeldovich mechanism of emission of nitrogen oxides. Combustion rate is high. As a result the Fenimore mechanism of "fast nitrogen oxides" has no chance to be progressing, and $\mathrm{NO}_{\mathrm{x}}$ emissions in appreciable quantities are excluded. Energy costs are comparable with spark ignition. Practical Relevance. The studied technology is designed for low emission internal combustion engines, power gas turbines, gas compressor units, fueled by natural gas.

Keywords

ecology, low-emission combustion chambers, quasi-optical microwave radiation, cold nonequilibrium plasma, lean-burn, emission of nitrogen oxides

Acknowledgements

The study was sponsored by the Ministry of Education and Science of the Russian Federation (agreement No 14.575.21.0057, unique applied research identifier RFMEFI57514X0057)

\section{Введение}

О задаче проектирования малоэмиссионных камер сгорания (МЭКС). Сжигание углеводородного горючего сопровождается выбросами в атмосферу окислов азота $\mathrm{NO}_{\mathrm{x}}$ и угарного газа СО. Выбросы $\mathrm{NO}_{\mathrm{x}}$ являются одной из основных причин образования фотохимического смога. Взаимодействуя с парами воды, они образуют азотную кислоту и вместе с оксидами серы являются причиной образования кислотных дождей. Повышенное содержание $\mathrm{NO}_{x}$ оказывает вредное воздействие на здоровье человека, поэтому в разных странах принимаются меры по снижению и ограничению максимально допустимых концентраций $\mathrm{NO}_{\text {х }}$ в выбросах электростанций, газотурбинных установок (ГТУ), автомобилей, самолетов и т.д. Двигатели транспортных средств, газовые турбины электростанций и газоперекачивающих агрегатов вместе ответственны за 36\% эмиссии $\mathrm{NO}_{x}$ и СО [1]. Первые ограничения на выбросы $\mathrm{NO}_{\mathrm{x}}$ были введены в 1986 г. (ICAO), в 1990 г. они были ужесточены на 20\%, в 2000 г. - еще на 16\%, в 2005 г. - на 12\%. К 2020 г. общее снижение выбросов $\mathrm{NO}_{\mathrm{x}}$ должно составить 80\%. В России в соответствии с научнотехнической политикой ОАО «ГАЗПРОМ» в области газоперекачивающей техники необходимо обеспечить к 2020 г. показатель эмиссии $\mathrm{NO}_{\mathrm{x}}<25$ мг/нм ${ }^{3}$. Именно поэтому всеми ведущими моторостроительными корпорациями приняты программы разработки МЭКС [1, 2].

Механизмы образования $\mathrm{NO}_{\mathbf{x}}$. Образование оксидов азота идет по трем основным механизмам [3]. Первый - механизм Зельдовича - термическое окисление азота воздуха при температурах более 1275 К. Наиболее активно образование «термических» оксидов азота идет при температурах больше

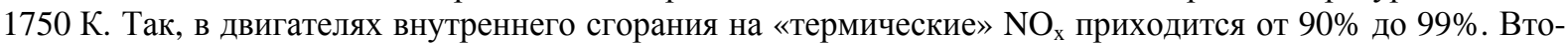
рой - механизм Фенимора - образование «быстрых» оксидов в результате столкновения во фронте горения углеводородных радикалов с молекулами азота. Процесс образования «быстрых» оксидов азота начинается уже при температуре от 1000 К и сравнительно слабо зависит от температуры. Третий - так называемый механизм $\mathrm{N}_{2} \mathrm{O} / \mathrm{NO}_{2}$ (группа реакций, в которой $\mathrm{N}_{2} \mathrm{O}$ выступает в качестве промежуточной стадии образования NO) - не актуален для двигателей, работающих на газе, но на него приходится до

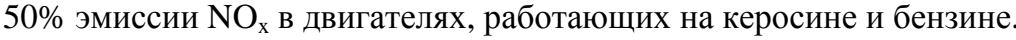

Основы теории окисления азота были заложены Зельдовичем [4]. В частности, им было показано, что образование $\mathrm{NO}_{x}$ не связано непосредственно с горением. В настоящее время расчет процесса окисления азота ведут с помощью полных или усеченных систем уравнений химической кинетики [5]. Существующие методики позволили наметить основные способы снижения эмиссии $\mathrm{NO}_{\mathrm{x}}$ и предложить принципиальные конструктивные решения МЭКС.

Типовые схемы МЭКС. В ГТУ горение носит диффузионный характер с очень узким температурным диапазоном, в котором эмиссия $\mathrm{NO}_{\mathrm{x}}$ и СО одновременно находятся в пределах нормы (рис. 1).

Основным способом снижения эмиссии $\mathrm{NO}_{x}$ является обеспечение устойчивого сжигания предельно бедных смесей и сокращение времени пребывания топливной смеси в области высоких температур (T>1900 К) до 5-6 мс. При коэффициенте избытка воздуха $\alpha$, близком к единице, когда отношение количества воздуха к количеству топлива (AFR - air fuel rate) соответствует стехиометрическому соот- 
ношению (15,6:1 при нормальных условиях для смеси пропана с воздухом), температура пламени макси-

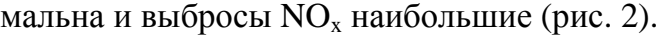

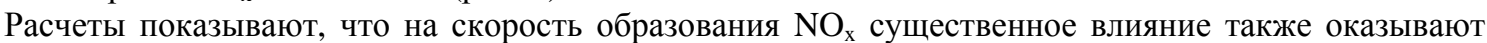
два механизма. Первый - механизм Махе, связанный с неравномерностью температурного поля, например, при постоянном искровом зажигании, когда скорость образования оксидов увеличивается. Второй эффект «закалки» оксидов при быстром нагревании и охлаждении, при котором скорость протекания реакций окисления, наоборот, существенно тормозится [6].

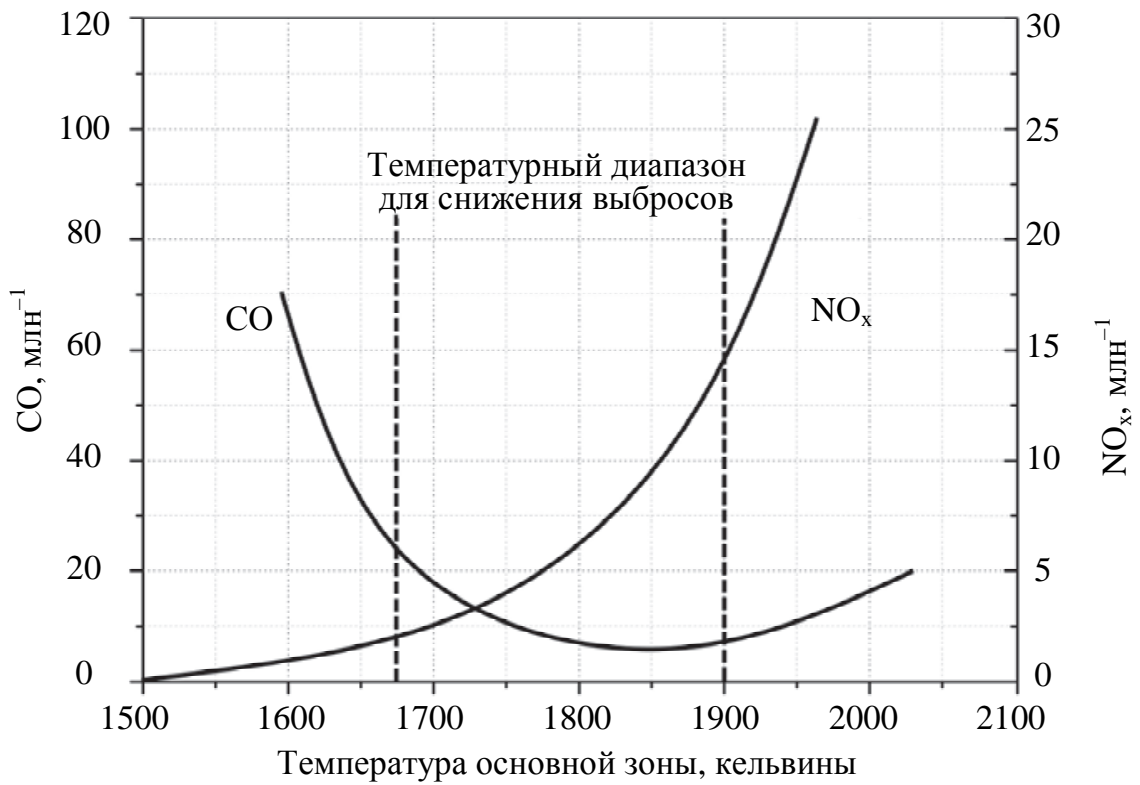

Рис. 1. Температурный диапазон для снижения выбросов СО и NO [6]

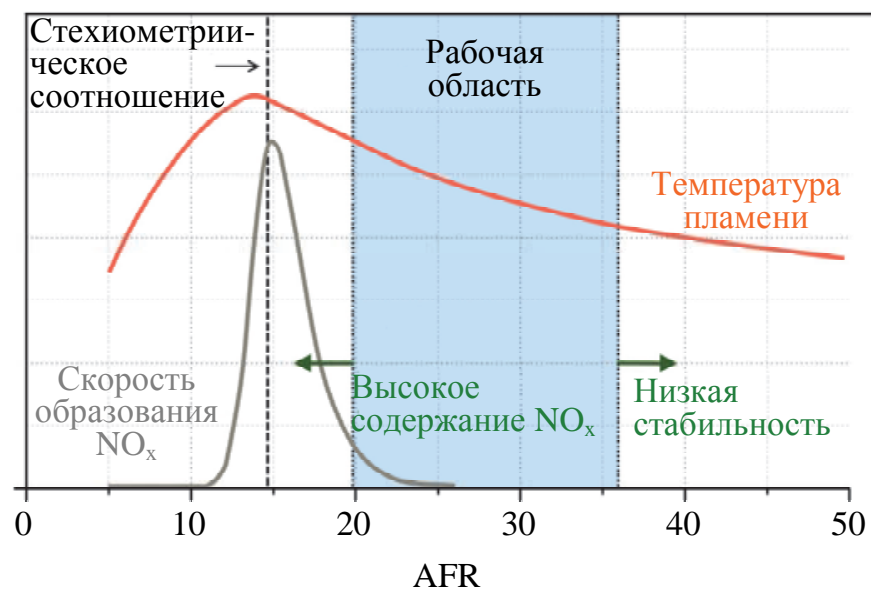

Рис. 2. Качественный характер зависимости уровня эмиссии $\mathrm{NO}_{x}$ и температуры пламени от отношения количества воздуха к количеству топлива (AFR - air fuel rate)

Механизм Махе стараются исключить за счет выравнивания температурного поля. И, наоборот, положительный эффект «закалки» оксидов пытаются использовать путем быстрого охлаждения топливной смеси за счет энергичного подмешивания холодного воздуха.

МЭКС:

Рассмотренные выше принципы приводят к нескольким типовым схемам организации горения в

- схема RQL (Reach Quench Lean), горение обогащенной смеси при $\alpha=0,5-0,7$ с последующим быстрым подмешиванием воздуха и охлаждением топливной смеси, быстрым (1-2 мс) переходом через стехиометрию в бедную смесь с $\alpha>2,4$ и догоранием обедненной смеси;

- схема LPP/LDI (Lean Premixed Prevaporized/Lean Direct Injection), горение обедненной предварительно смешанной смеси, схемы LPP и LDI отличаются только способом подачи топлива.

MЭKC RQL имеют преимущество перед LPP/LDI с точки зрения более широкого диапазона устойчивой работы. Основной задачей проектирования MЭКC RQL является обеспечение такого закона диффузионного горения, чтобы температура факела по длине камеры сгорания изменялась плавно и не пре- 


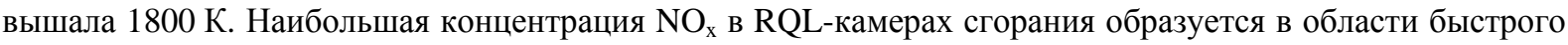
подмешивания холодного воздуха.

MЭКC LPP/LDI со сжиганием предварительно перемешанной бедной топливной смеси имеют больший потенциал снижения эмиссии $\mathrm{NO}_{\mathrm{x}}$ по сравнению c RQL. Обычно такие MЭКС выполняют двухзонными. Одна зона обеспечивает сжигание бедной смеси на номинальных режимах, другая является дежурной и используется на режиме малого газа или для стабилизации основного пламени.

К недостаткам существующих МЭКС следует отнести их большие габариты и конструктивную сложность. Как отмечалось в работе [7], для поджигания особо бедных смесей, а также стабилизации их горения можно использовать стримерный глубоко подкритический разряд, инициированный квазиоптическим СВЧ-излучением [8]. При этом стримерный разряд играет ту же роль, что и дежурная секция в MЭKC LPP/LDI, в которой сжигается богатая топливная смесь.

Ниже рассматриваются результаты эксперимента по сжиганию смеси пропана с воздухом. Для инициирования горения используется глубоко подкритический стримерный разряд, т.е. разряд, образованным полем с напряженностью намного меньше энергии пробоя воздуха. Получено существенное ускорение горения, равномерный температурный фронт, и подтверждена возможность сжигания бедных топливных смесей с избытком воздуха, соответствующим пределу воспламенения и даже выше.

\section{Методика проведения эксперимента}

Сотрудниками Московского радиотехнического института Российской Академии наук (МРТИ РАН) был разработан и исследован способ инициирования в газе стримерного разряда в квазиоптическом СВЧ-излучении [9], энергия которого намного меньше энергии электрического пробоя газа (так называемые глубоко подкритические разряды).

В установку, схема которой изображена на рис. 3, входит СВЧ-генератор, генерирующий электромагнитные колебания с частотой $f \approx 3 \cdot 10^{9}$ Гц или длиной волны $\lambda=8,9$ см, при длительности СВЧ-импульса $\tau_{\text {имп }}=40$ мкс. Электромагнитные колебания распространяются по элементам, формирующим линейно поляризующий квазиоптический СВЧ-пучок поперечным диаметром 60 см. Излучение поступает на фокусирующее зеркало. В области фокуса поперечный размер СВЧ-пучка примерно равен 10 см и имеет характерную протяженность около 15 см. В элементы, формирующие СВЧ-излучение,

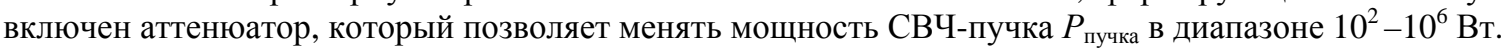

В фокус установки помещался инициатор разряда (инициатор пробоя воздуха), представлявший собой полуволновой электромагнитный вибратор. Он позволяет реализовать стримерный СВЧ-разряд при атмосферном давлении воздуха и энергии поля в сотни раз меньше энергии пробоя.

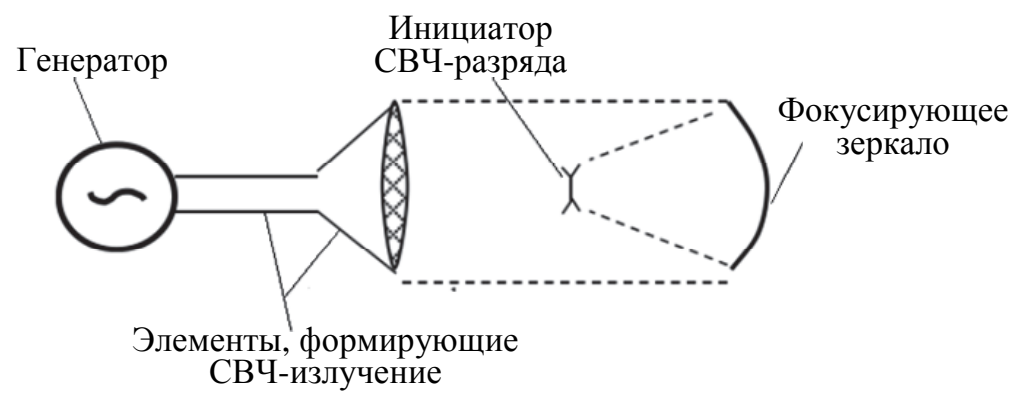

Рис. 3. Схема экспериментальной установки для инициирования стримерного разряда

Непосредственно к инициатору прикреплялся резиновый шарик диаметром около 10-15 см, наполненный смесью пропана и воздуха. При подаче импульса длительностью около 40 мкс к инициатору подводится энергия около 1 Дж. Максимальная располагаемая мощность импульса - порядка 1 МВт. При этом внутри шарика пробегает стримерный разряд, поджигающий смесь (рис. 4). В результате шарик лопается. Коэффициент $\alpha$ избытка воздуха изменялся в диапазоне $0,25-1,5, \alpha=1$ соответствует стехиометрическому соотношению воздуха и топлива (15,6:1 для смеси пропана с воздухом). Для изучения влияния напряженности СВЧ-поля на характер горения и тип генерируемого разряда инициатор помещался точно в фокусе зеркала установки, а также смещался на 40 мм от фокуса и на 45 мм. Предварительно проведенные эксперименты показали, что во втором случае образуется разряд переходного типа, а в третьем - присоединенного диффузного.

Развитие процесса горения сравнивалось для случаев стримерного и искрового зажигания. Во всех случаях подведенная энергия составляла около 1 Дж. Распространение фронта пламени фиксировалось на скоростную камеру Phantom v.2511, имеющую скорость съемки до 750000 кадров/с. Измерялись: время протекания процесса до того момента, когда шарик лопался, скорость распространения фронта горения, время индукции от момента разряда до начала реакции горения. 


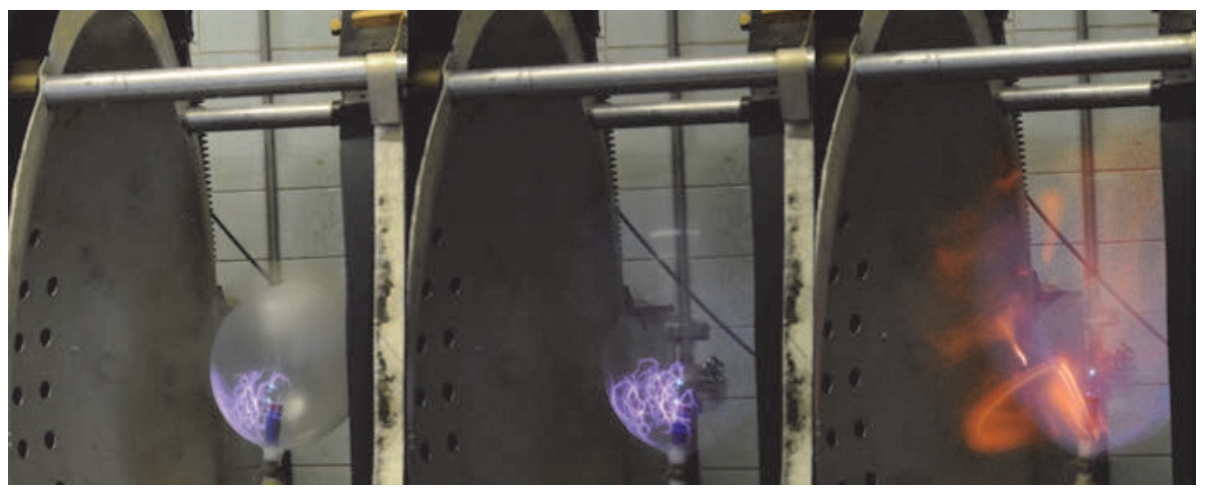

Рис. 4. Поджигание шарика, наполненного пропаном, стримерным разрядом. Размер шарика на левом снимке - 15 см

\section{Обсуждение результатов}

Сравнение искрового и стримерного зажигания. Первым был проведен эксперимент с искровым инициированием горения стехиометрической смеси воздуха и пропана. Воздушный шарик надувался топливной смесью до диаметра примерно 15 см и поджигался автомобильной свечой. В результате развивалось классическое диффузионное горение (см. кинограмму на рис. 5).

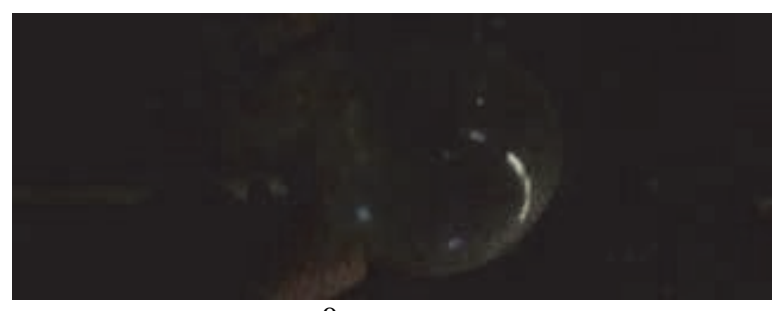

$0 \mathrm{c}$

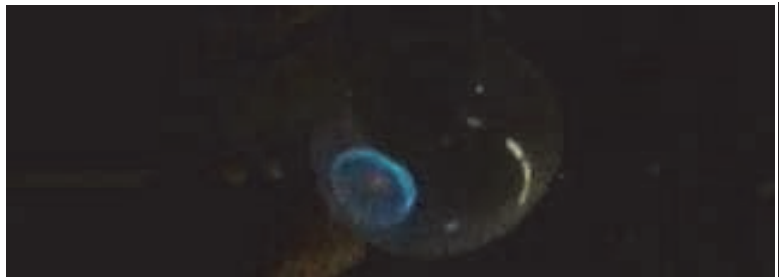

$0,0092 \mathrm{c}$

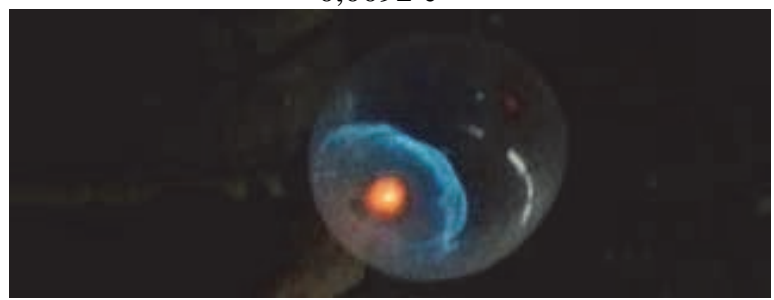

$0,0258 \mathrm{c}$

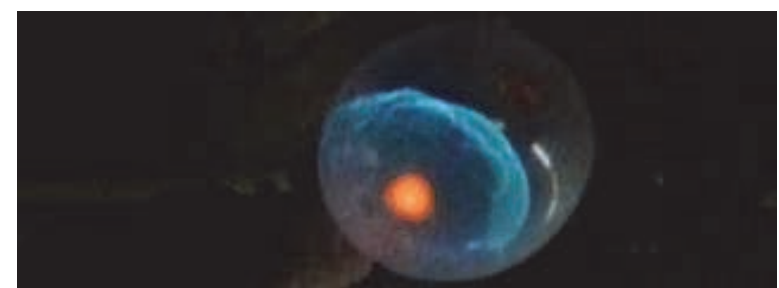

$0,0425 \mathrm{c}$

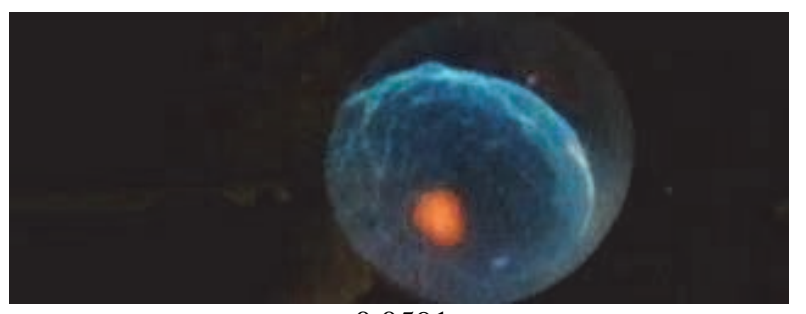

$0,0591 \mathrm{c}$

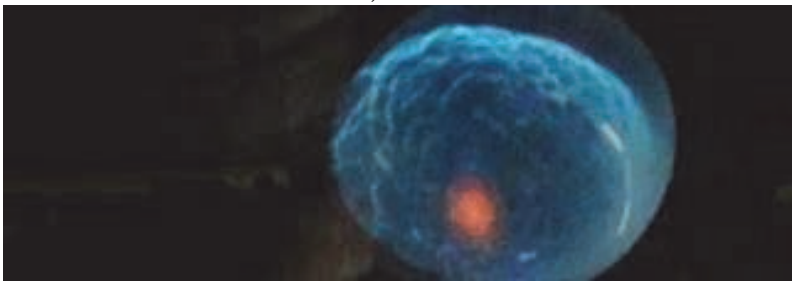

$0,0758 \mathrm{c}$

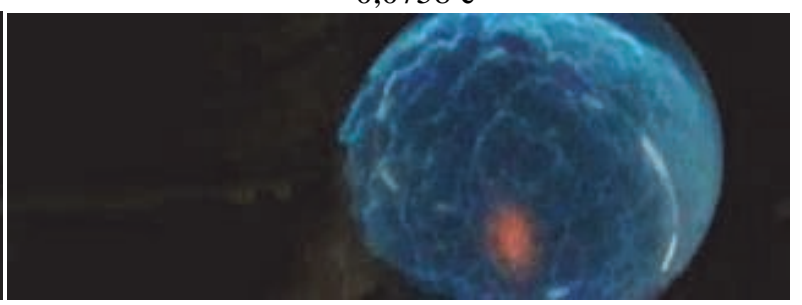

$0,0925 \mathrm{c}$

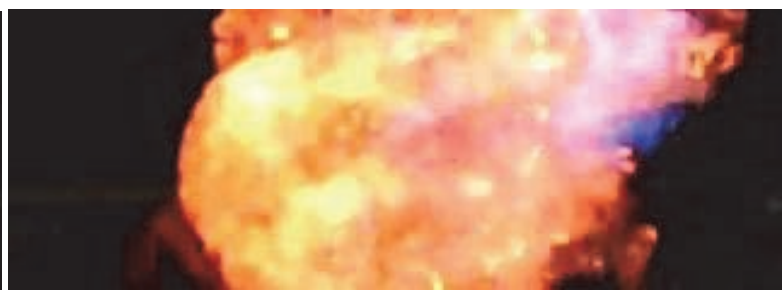

$0,1258 \mathrm{c}$

Рис. 5. Горение шарика, наполненного стехиометрической смесью пропана с воздухом, при искровом зажигании. Диаметр шарика на первом кадре - около 15 см

В месте воспламенения долгое время сохранялось яркое светящееся пятно оранжевого цвета, характерное для областей с большим градиентом температуры, в которых, в основном, и нарабатываются оксиды азота. Измеренная с помощью кинокамеры скорость распространения фронта пламени составила 1,5-2 м/с. Пламя имело голубовато-зеленоватый оттенок, что указывает на наличие в спектре свечения 
желтых линий, характерных для свечения частиц сажи и оксида азота. В момент, когда шарик лопнул, произошел выброс яркого желтого турбулентного пламени, которое продолжало светиться в течение еще 0,1 с. Характер пламени указывает на то, что сгорание пропана произошло не полностью, и поступление большого избытка кислорода вызвало увеличение температуры и интенсивное свечение частиц сажи и несгоревшего топлива.

Аналогичный эксперимент был проведен при инициировании горения стримерным разрядом. Наблюдавшаяся картина горения (рис. 6) радикально отличалась от случая искрового зажигания. Скорость распространения фронта пламени составляла 6-10 м/с. Шарик лопнул в два раза быстрее, чем при искровом зажигании. Пламя имело ровный фиолетовый цвет, характерный для горения чистого природного газа. Оранжевое пятно не появлялось. Однако фронт пламени был сильно турбулентным, и на его изломах образовались многочисленные так называемые «горячие» точки, из которых может развиться детонация. Они видны на фотографиях как области красного цвета. После того, как шарик лопнул, никакого выброса пламени не произошло, не было и послесвечения. Это говорит в пользу того, что пропан сгорел полностью.

Таким образом, инициирование зажигания стримерным разрядом радикально изменило характер горения: в разы увеличилась скорость горения и полнота сгорания, не образовывалась сажа. По косвенным признакам можно сделать предположение, что $\mathrm{NO}_{\text {х }}$ выделялись в минимальном объеме, так как светящиеся оранжевые области, характерные для больших градиентов температуры, отсутствовали. Кроме того, анализ кадров кинограммы позволил сделать предположение, что зажигание происходило сразу в значительном объеме, т.е. определялось не теплопроводностью, а каким-то другим механизмом.

Поджигание бедной смеси и сравнение типов разрядов. Эксперименты со стримерным зажиганием были повторены для $\alpha=0,25,0,33,0,4,0,5$, т.е. при количестве топлива меньше предела воспламенения $(\alpha=0,56)$.

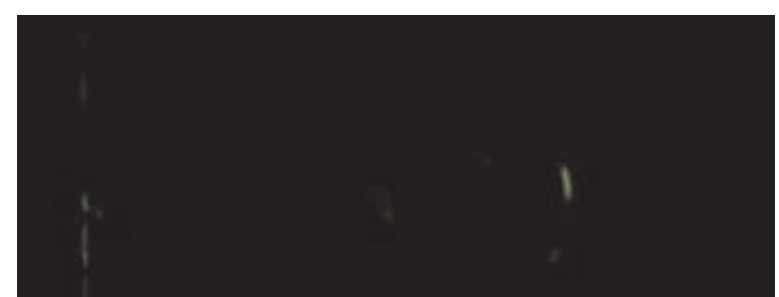

$0 \mathrm{c}$

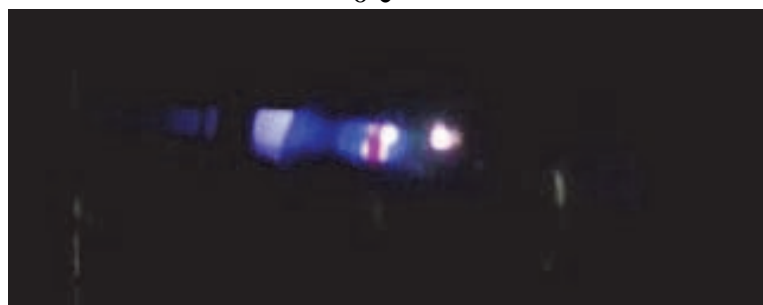

$0,0008 \mathrm{c}$

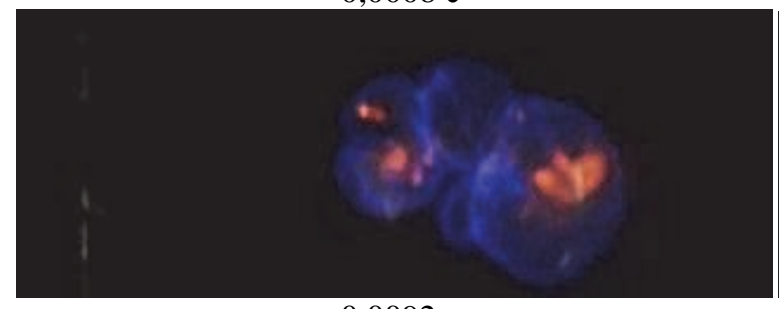

0,0092 c

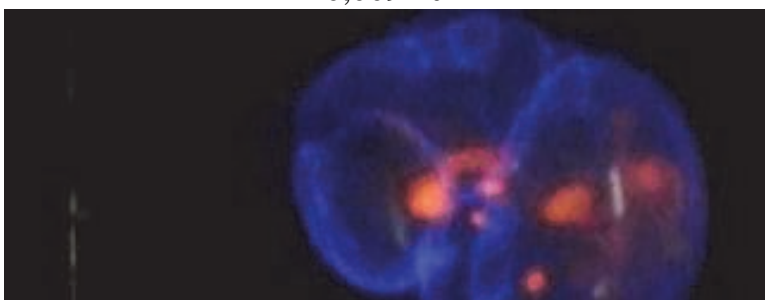

$0,0175 \mathrm{c}$

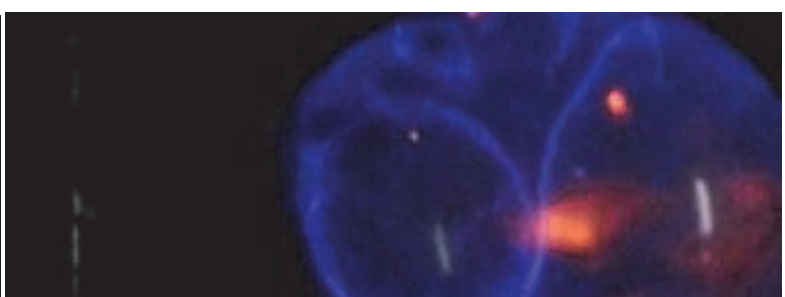

0,0258 c

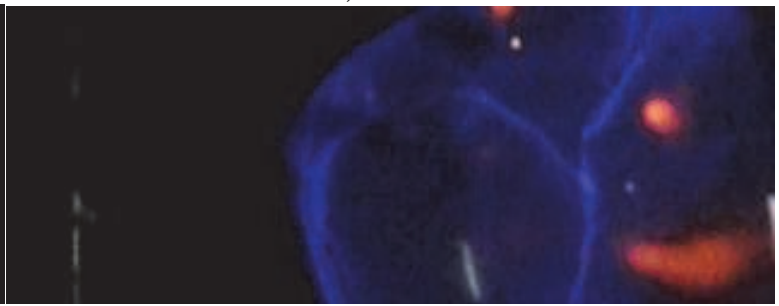

0,0342 c

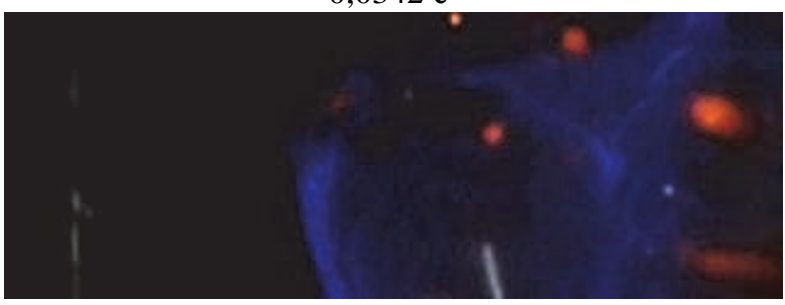

0,0425 c

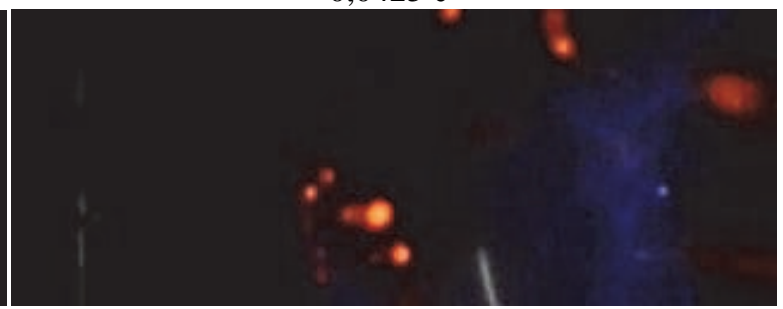

0,0508 c

Рис. 6. Горение шарика, наполненного стехиометрической смесью пропана с воздухом, при стримерном зажигании. Масштаб такой же, как на рис. 5 
При $\alpha=0,5$ воспламенение произошло, при меньших $\alpha-$ нет. Таким образом, было подтверждено, что при помощи стримерного разряда можно разжигать очень бедную топливную смесь, но только в разумных пределах. Эксперименты показали, что горение бедной смеси происходит примерно в два раза медленнее, чем богатой, зато отличается чистотой и практически полным отсутствием «горячих» точек. После того как шарик лопается, выхлоп пламени и послесвечение полностью отсутствуют.

Были исследованы присоединенный разряд и разряд переходного типа для зажигания стехиометрической смеси. Горение, инициированное присоединенным разрядом, оказалось похожим на таковое при искровом зажигании. Пламя - диффузионное. Скорость распространения фронта пламени - примерно 1-2 м/с. Но полнота сгорания выше, выхлоп пламени после того, как лопнул шарик, не такой яркий. Сам разряд не похож на стримерный и представляет собой небольшое плазменное образование с диффузной структурой. Воспламенение носит точечный характер, как и при искровом зажигании. Можно сделать вывод, что присоединенный разряд не дает заметных преимуществ по сравнению с искровым зажиганием, а механизм воспламенения в данном случае - тепловой.

Переходный разряд, подобно стримерному, имеет развитую структуру плазменных каналов, но занимаемый ими объем намного меньше. Характер горения очень похож на горение при зажигании стримерным разрядом, скорость распространения фронта пламени сопоставима, но начальный объем воспламенения существенно меньше, поэтому общее время сгорания смеси больше, а полнота сгорания меньше, чем при стримерном разряде.

Тем не менее, можно сделать вывод, что механизм поджигания смеси у стримерного разряда и разряда переходного типа - общий. Отличия в процессе горения объясняются меньшим объемом, в котором развивается переходный разряд, и меньшим количеством подведенной энергии. А вот горение при поджигании присоединенным разрядом имеет качественно иной характер и подобно горению при искровом поджигании. Стримерный и переходный разряд отличаются от присоединенного диффузного разряда развитой структурой плазменных нитей. Можно предположить, что иной характер воспламенения и горения определяется именно нитевидной структурой стримерного и переходного разрядов.

Для проверки этой гипотезы были проведены отдельные эксперименты со скоростью съемки, увеличенной до 1000000 кадров/с. Это позволило подробно рассмотреть развитие начальной фазы горения. На рис. 7 приведена кинограмма стримерного разряда для наиболее типичного случая горения при $\alpha=0,5$. В левом нижнем углу каждого кадра приведено время с точностью до 1 мкс. При такой скорости съемки камера могла вести съемку только в черно-белом режиме.
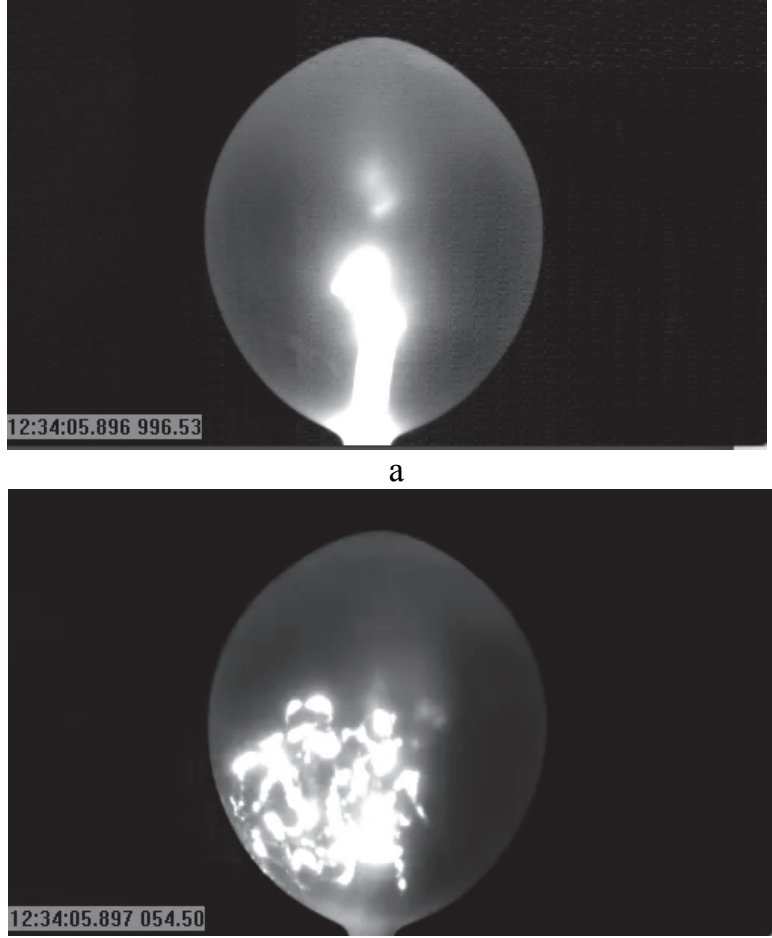

B

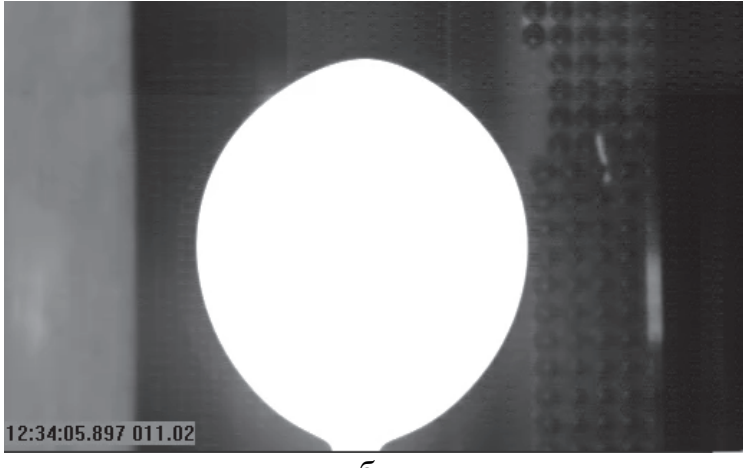

6

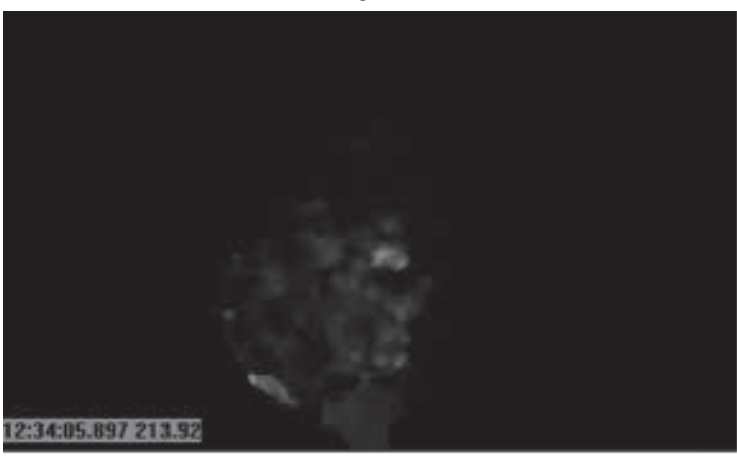

$\Gamma$

Рис. 7. Развитие стримерного разряда: зажигание разряда (а); яркая вспышка (б); развитая стримерная структура (в); след от погасшего разряда (г)

В начальный момент времени под воздействием импульса СВЧ-излучения зажигается разряд (рис. 7, а). Примерно через 10-15 мкс следует яркая вспышка, сопровождающаяся фиолетовым свечени- 
ем (рис. 7, б), еще примерно через 40 мкс наблюдается развитая стримерная структура (рис. 7, в), затем в течение 50-60 мкс разряд гаснет, и на его месте остается след (рис. 7, г).

Горение начинается в точности на месте следа от разряда (рис. 8, а) примерно через 150 мкс. Таким образом, время индукции при инициировании горения стримерным разрядом уменьшается в 710 раз по сравнению с обычным тепловым механизмом воспламенения. Пламя в начальный момент времени - сильно турбулентное. Воспламенение происходит сразу в большом объеме и очень быстро развивается на начальном этапе (рис. 8, б). Это однозначно указывает, что распространение пламени не связано с эффектом теплопроводности, и механизм воспламенения - какой-то другой.

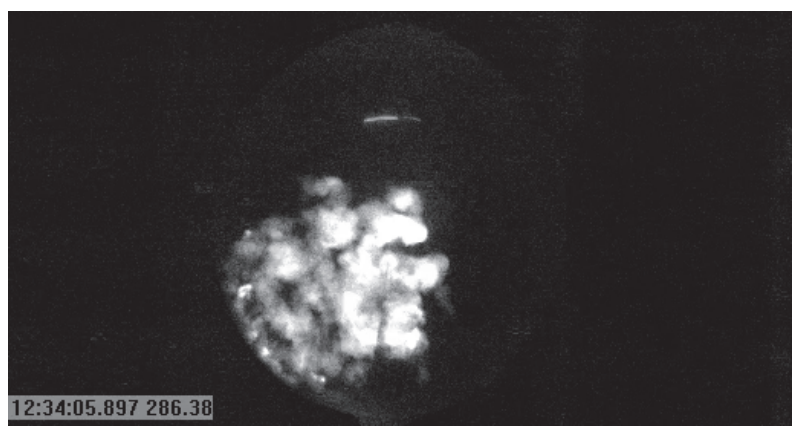

a

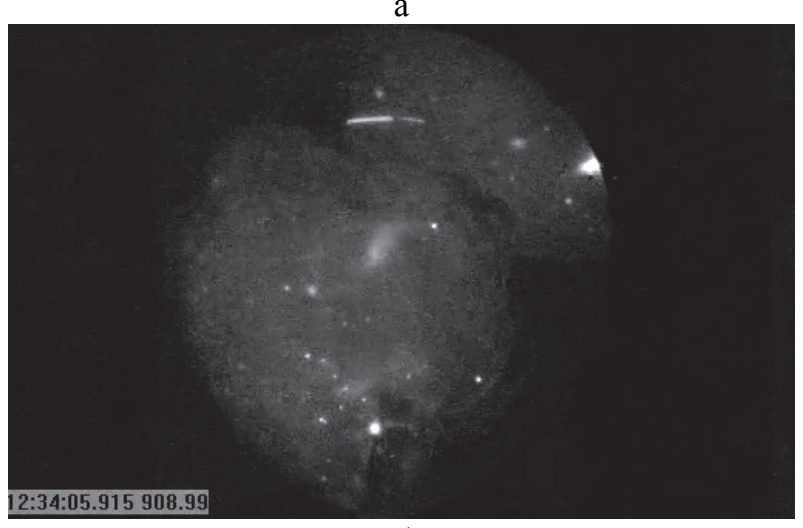

6

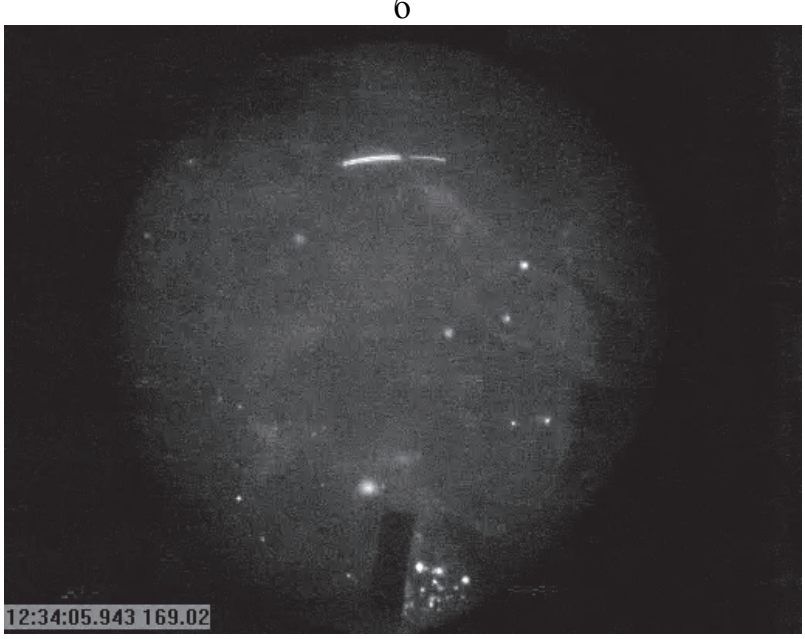

B

Рис. 8. Горение, инициированное стримерным разрядом: воспламенение топливной смеси (а); развитие турбулентного фронта горения (б); развитая область горения (в)

Эксперимент был повторен для разряда переходного типа. Единственное отличие заключалось в том, что в данном случае разряд занимал меньшую область и, соответственно, горение начиналось в меньшем объеме. Эксперимент с присоединенным диффузным разрядом показал его полную аналогию с искровым поджиганием (рис. 9). Разряд зажигается в виде плазменного облака (рис. 9, а). Примерно через 2-3 мс (рис. 9, б) начинается воспламенение смеси, т.е. время индукции в точности соответствует обычному тепловому режиму воспламенения. На месте зажигания образуется яркое пятно с большим градиентом температуры, которое остается видимым примерно 10 мс (рис. 9, в). Затем область горения и высокой температуры занимает весь объем (рис. 9, г). 

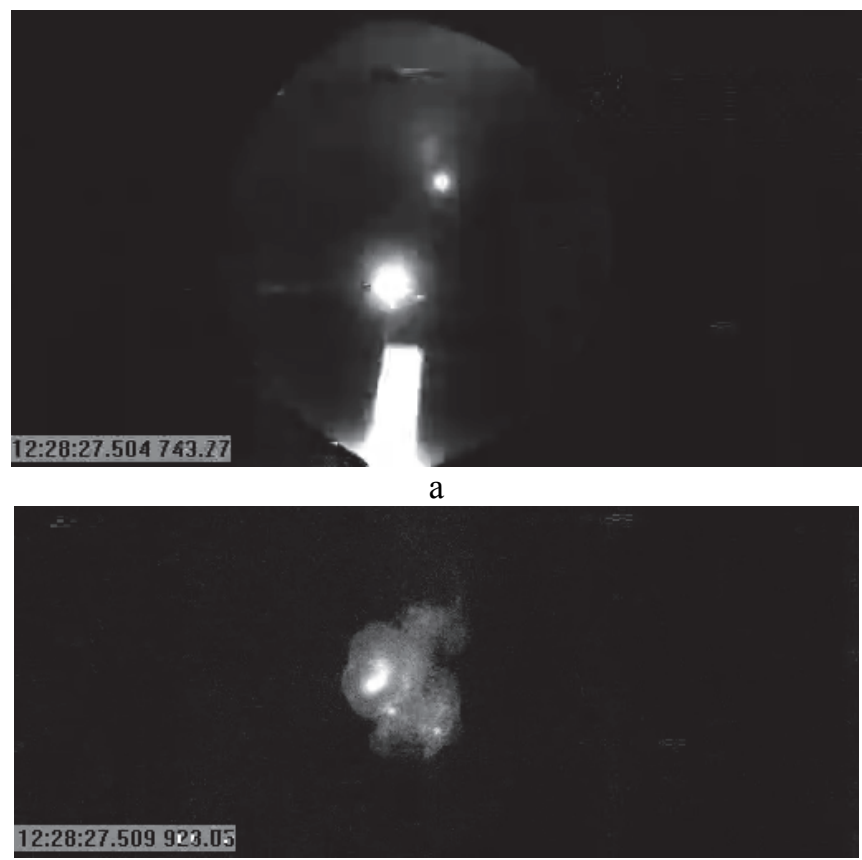

6
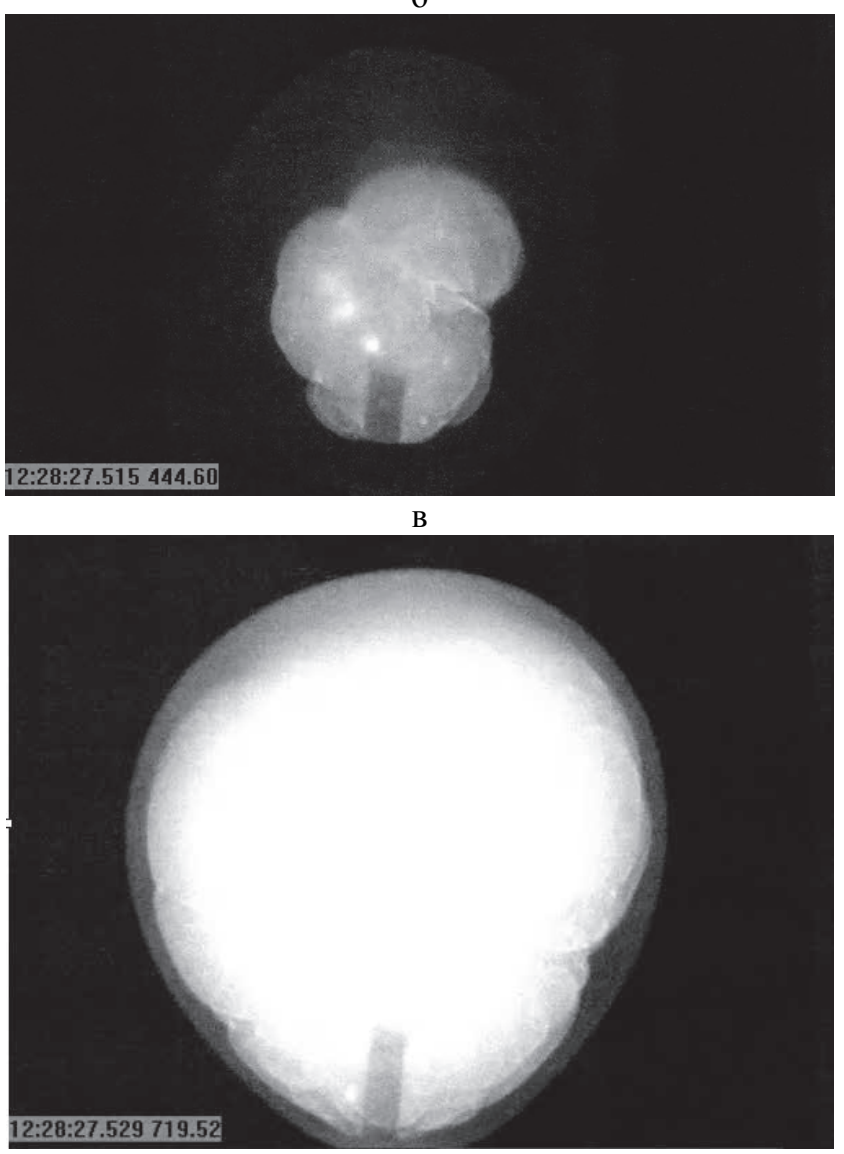

$\Gamma$

Рис. 9. Горение, инициированное присоединенным разрядом: зажигание разряда (а); воспламенение топливной смеси (б); развитие фронта горения (в); развитая область горения (г)

В ряде работ $[8,9]$ утверждается, что стримерный разряд сопровождается мощным ультрафиолетовым свечением, вызывающим лавинообразный рост числа свободных электронов. Действительно, еще в работах $[10,11]$ возникновение нитевидных плазменных каналов однозначно связывается с развитием процесса ионизационно-перегревной неустойчивости в плазме СВЧ-разряда, которая сопровождается мощным ультрафиолетовым излучением из зоны разряда. Именно этим стримерный и переходный разряды и отличаются от присоединенного диффузного. СВЧ-разряд возбуждает атомы кислорода, в резуль- 
тате чего генерируется мощное ультрафиолетовое излучение, которое вызывает образование холодной неравновесной плазмы с лавинообразным нарастанием числа свободных электронов. Выполненные эксперименты показали, что стримерный разряд распространяется со скоростью порядка 5 км/с, поэтому инициирование зажигания происходит сразу по всему объему, куда проникают плазменные нити. Температура топливной смеси в месте инициирования зажигания не превышает $400 \mathrm{~K}$.

Таким образом, можно сделать вывод, что выявленные в ходе исследования преимущества зажигания топливной смеси стримерным разрядом связаны именно с ультрафиолетовым излучением. Что непосредственно отвечает за сокращение времени индукции и увеличение скорости распространения пламени - само ультрафиолетовое излучение или вызываемая им лавина электронов - предстоит еще выяснить.

\section{Заключение}

При инициировании зажигания стримерным разрядом получено увеличение скорости горения и полноты сгорания примерно в четыре раза, инициирование горения особо бедной топливно-воздушной смеси с концентрацией топлива меньше предела воспламенения при нормальных условиях. Затраты подведенной энергии сопоставимы с искровым зажиганием. Косвенные признаки указывают на практически полное отсутствие окислов азота в продуктах сгорания, что, видимо, объясняется большой скоростью горения и отсутствием областей с высокой температурой.

Стримерное СВЧ-зажигание может быть применено в двигателях внутреннего сгорания вместо традиционного зажигания. Эксперименты показали, что время сгорания топлива напрямую зависит от того, какую долю объема, заполненного топливно-воздушной смесью, занимает разряд. Чем разряд больше, тем меньше время и больше полнота сгорания.

Исследования должны быть продолжены. Необходимо провести эксперименты в условиях, имитирующих работу камеры сгорания газотурбинного двигателя и двигателя внутреннего сгорания, а также выполнить прямые измерения концентрации $\mathrm{NO}_{\mathrm{x}}$ в продуктах сгорания. Необходимо также выяснить, с чем непосредственно связан механизм воспламенения, с лавиной электронов или с ультрафиолетовым излучением. Если окажется, что непосредственной причиной является излучение, это откроет новые возможности по разработке оптических систем зажигания, в том числе, для перспективных детонационных двигателей.

\section{Литература}

1. Carlson D. GE Aviation: Perspectives on Clean, Efficient Engines. 2013.

2. Bradley A. Engine design for the environment // RAeS. Hamburg, 2010.

3. Заев И.А., Потапкин Б.В., Федоров С.А., Куприк В.В.. Моделирование эмиссии токсичных веществ из камеры сгорания стационарной газотурбинной установки // Изв. вузов. Авиационная техника. 2014. №2. С. 49-54.

4. Зельдович Я.Б., Садовников П.Я., Франк-Каменецкий Д.А. Окисление азота при горении. М.: Изд. АН CCCP, 1947. 148 c.

5. Strelkova M.I., Kirillov I.A., B Potapkin B.V., Safonov A.A., Sukhanov L.P., Umanskiy S.Ya., Deminsky M.A., Dean A.J., Varatharajan B., Tentner A.M. Detailed and reduced mechanisms of jet a combustion at high temperatures // Combustion Science and Technology. 2008. V. 180. N 10-11. P. 1788-1802. doi: 10.1080/00102200802258379

6. Лефевр А. Процессы в камерах сгорания ГТД. М.: Мир, 1986. 566 с.

7. Булат П.В., Есаков И.И., Волобуев И.А., Грачев Л.П. О возможности ускорения горения в камерах сгорания перспективных реактивных двигателей при помощи глубоко подкритического СВЧ-разряда // Научно-технический вестник информационных технологий, механики и оптики. 2016. Т. 16. № 2. С. 382-385. doi: 10.17586/2226-1494-2016-16-2-382-385

8. Александров К.В., Грачев Л.П., Есаков И.И., Федоров В.В., Ходатаев К.В. Области реализации различных типов СВЧ-разряда в квазиоптических электромагнитных пучках // ЖТФ. 2006. Т. 76. № 11. C. $52-60$.

9. Khodataev K.V. The nature of surface MW discharges // Proc. $48^{\text {th }}$ AIAA Aerospace Sciences Meeting and Exhibition. Orlando, Florida, 2010. Art. 2010-1378.

10.Ким А.В., Фрайман Г.М. О нелинейной стадии ионизационно-перегревной неустойчивости в высокочастотном разряде высокого давления // Физика плазмы. 1983. Т. 9. № 3. С. 613-617.

11.Богатов Н.А., Голубев С.В., Зорин В.Г. Механизм образования плазменного ореола вокруг СВЧ разряда // Физика плазмы. 1986. Т. 12. №11. С. 1309-1375.

Булат Павел Викторович

кандидат физико-математических наук, кандидат экономических наук, заведующий международным научным подразделением, Университет ИТМО, Санкт-Петербург, 197101, Российская Федерация, pavelbulat@mail.ru 
Булат Михаил Павлович

Есаков Игорь Иванович

Волобуев Игорь Алексеевич

Грачев Лев Петрович

Денисенко Петр Владимирович

Pavel V. Bulat

Mikhail P. Bulat

Igor I. Esakov

Igor A. Volobuev

Lev P. Grachev

Petr V. Denissenko
- аспирант, Университет ИТМО, Санкт-Петербург, 197101, Российская Федерация, bulat_mh@mail.ru

- доктор физико-математических наук, заместитель генерального директора, Московский радиотехнический институт РАН, Москва, 117519, Российская Федерация, esakov@mrtiran.ru

- аспирант, Университет ИТМО, Санкт-Петербург, 197101, Российская Федерация; генеральный директор, ООО «ВНХЭнерго», Санкт-Петербург, 198035, Российская Федерация, Volobuev_ig@mail.ru

- $\quad$ начальник отдела, Московский радиотехнический институт РАН, Москва, 117519, Российская Федерация, Esakov@mrtiran.ru

- кандидат физико-математических наук, научный сотрудник, Университет Уорвика, Ковентри, CV4 7AL, Великобритания, p.denissenko@gmail.com

- $\quad$ PhD, Scientific supervisor of International laboratory, ITMO University, Saint Petersburg, 197101, Russian Federation, pavelbulat@mail.ru

- postgraduate, ITMO University, Saint Petersburg, 197101, Russian Federation, bulat_mh@mail.ru

- D.Sc., Deputy general director for science, Moscow Radiotechnical Institute of the Russian Academy of Sciences, Moscow, 117519, Russian Federation, esakov@mrtiran.ru

- postgraduate, ITMO University, Saint Petersburg, 197101, Russian Federation; CEO (Chief Executive Officer), VNHEnergo, Saint Petersburg, 198035, Russian Federation, Volobuev_ig@mail.ru

- Head of plasma research department, Moscow Radiotechnical Institute of the Russian Academy of Sciences, Moscow, 117519, Russian Federation, Esakov@mrtiran.ru

- PhD, Associate Professor, Warwick University, Coventry, CV4 7AL, United Kingdom, p.denissenko@gmail.com 